Volume 2 Nomor 1, Maret 2020, Halaman 16-26

\title{
PEMBERDAYAAN DAN PENGEMBANGAN INDUSTRI KECIL MENENGAH DI KABUPATEN INDRAMAYU: KRUPUK KULIT
}

\author{
Nunung Nurhayati \\ Fakutas Ekonomi Universitas Wiralodra \\ hajinunung86@gmail.com
}

\begin{abstract}
Abstrak
Pengabdian merupakan salah satu kewajiban seorang dosen, pada pengabdian ini tim pengabdian terdiri dari dosen dan mahasiswa. Kegiatan pengabdian dilakukan di Pabrik Krupuk PD IKA dan dilaksanakan selama 3 minggu. Tujuan program pengabdian ini adalah memberikan pengetahuan kepada mahasiswa akan pentingnya berwirausaha, selain itu progam ini berusaha untuk meningkatkan perekonomian mitra. Usaha mahasiswa yaitu dengan menganalisis aspek keuangan, aspek sumberdaya manusia, aspek produksi/ operasional, dan aspek pemasaran. Pelaksanaan kegiatan meliputi perencanaan, pelaksanaan, dan pelaporan. Pengambilan data dilakukan melalui observasi langsung. Hasil pengabdian ini adalah aspek keuangan belum tercapai dengan baik, karena belum ada pencatatan administrasi. Aspek sumber daya manusia sudah baik, aspek pemasaran sudah baik dengan adanya bantuan dari mahasiswa. Aspek produksi sudah baik. Kesimpulan kegiatan pengabdian ini adalah setelah tim melakukan pendampingan, Pabrik Krupuk Kulit PD IKA berjalan dengan baik, hanya perlu manajemen keuangan yang lebih baik.
\end{abstract}

Kata Kunci : Ekonomi, Pabrik Krupuk, Aspek pembangun.

\begin{abstract}
Devotion is one of the obligations of a lecturer, in this service the devotion team consists of lecturers and students. The dedication activity was carried out at the PD IKA Krupuk Factory and carried out for 3 weeks. The goal of this service program rovide knowledge to students on the importance of entrepreneurship, besides this program seeks to improve the partner's economy. Student effort is to analyze the financial aspects, aspects of human resources, aspects of production / operations, and marketing aspects. Implementation of activities includes planning, implementation, and reporting. Data is collected through direct observation. The result of this dedication is that financial aspects have not been achieved properly, because there is no administrative record. The human resource aspect is good, the marketing aspect is good with the assistance from students. The production aspect is good. The conclusion of this dedication activity is that after the team did the mentoring, PD IKA's Krupuk Kulit Factory went well, just need better financial management.

Keywords: Economy, Crackers Factory, Development Asprc
\end{abstract}

DOI: https://doi.org/10.31943/abdi.v2i1.20 


\section{PENDAHULUAN}

Beranjak dari kebutuhan akan sumber daya manusia yang berkualitas, membuat setiap individu harus memiliki keunggulan untuk mampu bersaing dalam dunia kerja/bisns. Lebih lagi didorong oleh perkembangan globalisasi yang semakin pesat membuat persaingan di berbagai bidangpun semakin ketat. UKM harus bertahan dan kompetitif supaya dapat bersaing di jaman globalisasi (Sari \& Yasa, 2016). Kondisi ini tentu menjadi perhatian dunia pendidikan salah satunya perguruan tinggi. Oleh karena itu di Fakultas Ekonomi Universitas Wiralora menyelenggarakan mata kulia KKU ( Kuliah Kerja Usaha) sebagai salah satu komitmen untuk membina dan membentuk individu-individu yang memiliki keunggulan serta diharapkan dapat mengisi dan menjadi bagian dari pelaku bisnis / dunia kerja. Keunggulan yang dimaksud tentunya bukan hanya pada tataran ilmu pengetahuan dan teknologi saja tetapi juga keunggulan akan kemampuan skill (komunikasi,kerjasama,serta tanggung jawab).

Untuk mata kuliah KKU ini mempunyai bobot SKS sebesar 1 SKS. KKU wajib iikuti oleh seluruh mahasiswa program studi Manajemen di Fakultas Ekonomi Unwir. KKU dilaksanakan dalam kurun waktu 2 bulan, dalam jangka waktu yang sudah di tentukan mahasiswa akan diperkenalkan secara langsung pada praktik lapangan yang dilakukan oleh suatu Industri Kecil Menengah (IKM), Sekaligus akan diberi kesempatan kepada mahasiswa untuk mengaplikasikan ilmu yang telah didapatkan di bangku perkuliahan ke dalam lingkungan kerja.

Tim melaksanakan pengabdian masyarakat di IKM Krupuk Kulit PD IKA , dimana kegiatan utamanya yakni pembuatan krupuk yang berbahan dasar dari kulit ikan. Awal mulai berdirinya perusahaa sekedar hoby dari pemilik Industri yang senang dengan dunia bisnis lalu pemilik Industri meciptakan produk yang berbahan dasar kulit ikan untuk dijadikan krupuk dan usaha tersebut di didirikan sekitar tahun 2005 pada saat itu bisnis nya berjalan sesuai yang sudah direncanaka, pada saat itu pemilik Industri mendapat komplain dari konsumen bahwa bahan dasar ikan yang digunakan itu dikenal mengandung racun dan kurang layak untuk diolah menjadi krupuk, oleh karena itu pemilik Industri mencari bahan dasar ikan lain yang bisa 
diolah menjadi krupuk. Kemudian sekitar tahun 2014 Industri memulai usahanya kembali dengan menggati bahan dasar ikan lain yang tidak berbahaya dan menguji terlebih dahulu bahan dasar yang akan digunakan hasilnya baik dan layak untuk di kosumsi. Pemilik dan karyawan mempunyai tanggungjawab,disiplin dan terampil dalam kerjasama mengelola kegiatan usahanya, serta dalam upaya meningkatkan skala usaha dan peningkatan usaha kearah yang lebih produktif dan berkelanjutan.

Usaha krupuk kulit ikan ini masih tergolong baru dari awal pembentukannya, namun demikian perkembangan usahanya sudah berkembang dan mampu beraing di dunia pasar dengan produk yang di buat oleh perusaan lain, kesungguhan dan kekompakan pemilik dan anggota membuat kegiatan usaha berjalan sesuai apa yang sudah direncanakan dan terarah. Di dalam produksi Krupuk Ikan PD.IKA terdapat permasalahan dalam karyawan/ tenaga kerja diantaranya yaitu :

\section{Kedisplinan Kerja}

Disiplin kerja dapat didefinisikan sebagai sikap yang menunjukan ketaatan, kepatuhan, kesetiaan, keteraturan dan ketertiban dalam bekerja (Bariyah, 1999). Kedisplinan dalam bekerja harus selalu diterapkan oleh industri agar usaha dapat mencapai target sesuai rencana dan kondusif dalam melaksanakan kegiatan usaha. Oleh karena itu pemilik Industri harus tegas dalam menentukan waktu kerja yang sudah ditetapkan.

Dalam Produksi krupuk ikan PD.IKA ini karyawan nya kebanyakan berasal dari Ibu rumah tangga dan sebagian besar mereka mengurus keluarga dirumah terlebih daluhu sehingga jam kerja sedikit berkurang hal ini sangat berpengaruh dalam kegiatan produksi. Oleh karena itu pemilik Industri harus tegas dalam menghadapi hal tersebut, pemilik bisa dengan memberi sanksi tegas bagi karyawan yang tidak disiplin waktu jam kerja, agar karyawan kedepannya dapat disiplin dalam bekera sehingga Industri dapat berjalan dengan baik dan terarah.

2. Lingkungan kerja Produksi

Lingkungan kerja yang kurang mendukung untuk melakukan kegiatan produksi, misalnya ruangan/tempat untuk menggoreng tidak terdapat ventilasi 
udara sehingga pengap, gudang penyimpanan kulit ikan kering begitu bersih oleh karena itu, ini merupakan masalah yang ada. lingkungan kerja juga berpengaruh terhadap produktivitas kerja karyawan (Khoirul Ulum et al., 2018).

\subsection{Aspek Keuangan}

Pengetahuan mengenai pengelolaan sangatlah penting untuk mengembangkan UMKM (Widayanti et al., 2017). Permasalahan keuangan di Produksi Krupuk Ikan PD.IKA ini yaitu Pembukuaan yang belum ada / belum dibuat oleh Industri.

Pembukuan termasuk dalam pengelolaan keuangan yang menjadi salah satu inti dari keberhasilan usaha. Pemilik usaha Indutri Kecil Menengah (IKM) kesulitan dalam membuat laporan keuangan / data keuangan. Oleh karena itu pemilik cenderung sudah puas dengan keuntungan yang mereka peroleh tanpa memikirkan pembukuan pada Industri.

\subsection{Aspek Pemasaran}

Salah satu permasalahan yang di hadapi oleh UKM adalah pemasaran produk (Jayanti Mandasari et al., 2019). Permasalahan pemasaran yang ada di Produksi Krupuk Kulit PD.IKA ini yaitu:

1. Pemasaran yang masih Tradisional

Pemasaran produk yang masih tradisional ini merupakan cara pemasaran yang masih tergolong cukup rendah, karena daerah pemasarannya masih relatif kecil dalam hal ini kita tidak bisa memperluas pasar dan tidak dapat mengembangkan produk.

2. Pengemasan yang masih sederhana membuat daya tarik konsumen kurang diminati, sehingga ini menjadi salah satu faktor yang mempengaruhi produk tidak dilirik oleh konsumen.

\subsection{Aspek Produksi/ Oprasional}

Permasalahan produksi/operasional pada PD.IKA hanya terdapat pada Kendala cuaca. Cuaca menjadi salah satu faktor utama berjalannya produksi pada suatu Industri ini. Alternatif yang dibuat oleh Industri adalah dengan 


\section{ABDI WIRALODRA}

JURNAL PENGABDIAN KEPADA MASYARAKAT
ISSN 2656-5501 (Print)

ISSN 2714-8041 (Online)

memproduksi lebih banyak bahan baku, sedangkan pada musim hujan produksi dibantu menggunakan oven saat pengeringan kulit ikan.

\section{METODE}

Kegiatan program pengabdian masyarakat dilaksanakan di desa Babadan kecaamatan Sindang indramayu. Kegiatan dilakukan selama 1 bulan (16 Desember 2019 - 29 Januari 2020), melalui beberapa tahapan berikut:

1. Tahap Persiapan ;

a) Survey awal ke lokasi

b) Berkomunikasi dengan pihak pemilik pabrik

c) Meminta surat ijin untuk melakukan KKU di Pabrik Krupuk

d) Menggali informasi melalui perangkat desa dan mendokumentasikan potensi tempat pengabdian akan dilaksanakan

2. Tahap Pelaksanaan ;

a) Mengadakan pelatihan pembuatan akun pemasaran cara mengisi konten produk

b) Memberikan sosialisasi pembenahan kinerja dan disiplin kerja.

c) Membantu membuat laporan keuangan.

3. Tahap Evaluasi ;

Tahap evaluasi dilakukan hanya sebatas laporan.

\section{HASIL DAN PEMBAHASAN}

Kegiatan Program Pengabdian Kepada Masyarakat dimulai dengan melakukan kegiatan observasi awal dengan mendatangi pabrik krupuk dan interview kepada pemilik pabrik. Kegiatan observasi awal telah dilakukan pada tanggal 16 Desember 2019. Hasil observasi yaitu kurangnya kedisiplinan kerja para karyawan, kurangnya tertib administrasi keuangan, dan kurangnya publikasi pemasaran secara online. Berikut ini hasil pengabdian masyarakat di pabrik krupuk PD IKA. 


\section{Aspek Sumber Daya Manusia}

1. Menerapkan Kedisiplinan Karyawan

Waktu dilaksanakan : 3 Minggu

Target pencapaian $: 70 \%$

Alasan belum tercapai: mayoritas pekerja adalah ibu rumah tangga hal ini mengakibatkan pekerja sering terlambat datang ke tempat bekerja karena mengurus rumah tangga terlebih dahulu.

2. Lingkungan kerja

Waktu dilaksanakan : 3 Minggu

Target pencapaian : $: 50 \%$

Alasan belum tercapai: Pemilik Industri belum memiliki modal untuk membenahi/memperbaiki tempat kerja.

\section{Aspek Keuangan}

Membuat laporan keuangan

Waktu dilaksanakan : 5 minggu

Target Pencapaian : $: 30 \%$

Alasan belum tercapai: Dari awal berdirinya Industri tidak mempunyai laporan keuangan, kemudian ketika kami melakukan wawancara untuk memperoleh data sang pemilik menjawabnya tidak sesuai dengan pertanyaan yang kami ajukan (berbelit-belit)

\section{Aspek Pemasaran}

1. Membuatkan akun media sosial untuk menjualkan produk secara online

Waktu dilaksanakan : 2 Minggu

Target Pencapaian $\quad: 100 \%$

2. Membuat pengemasan secara modern agar dapat menarik konsumen

Waktu dilaksanakan : 3 Minggu

Target Pencapaian $: 100 \%$ 


\begin{tabular}{ll}
$\begin{array}{l}\text { ABDI WIRALODRA } \\
\text { JURNAL PENGABDIAN KEPADA MASYARAKAT }\end{array}$ & $\begin{array}{l}\text { ISSN 2656-5501 (Print) } \\
\text { ISSN 2714-8041 (Online) }\end{array}$ \\
\hline
\end{tabular}

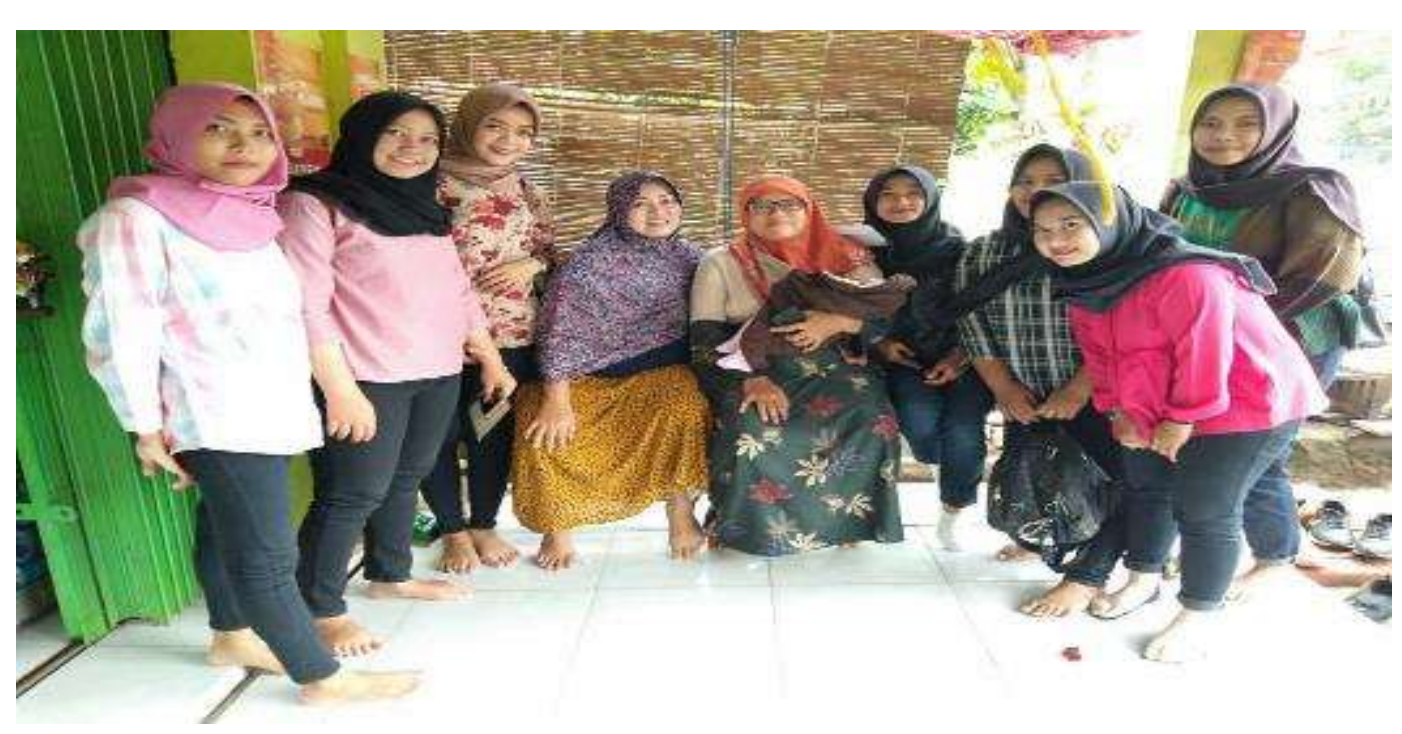

Gambar 1. Kegiatan Kunjungan Awal dan Menggali informasi di Industri

\section{Kecil Menengah (IKM)}

Pada Gambar 1 mendeskripsikan mmengenaik kunjungan awal tim pengabdian ke Industri Kecil Menengah di kabupaten Indramayu, setelah berdiskusi, dipilih PD IKA untuk menjadi mitra pada program pengabdian ini yang dibalut dalam KKU (Kuliah Kerja Umum). Program ini dilaksanakan berkelompok dengan jumlah peserte tiap kelompok adalah 6 sampai 7 orang.

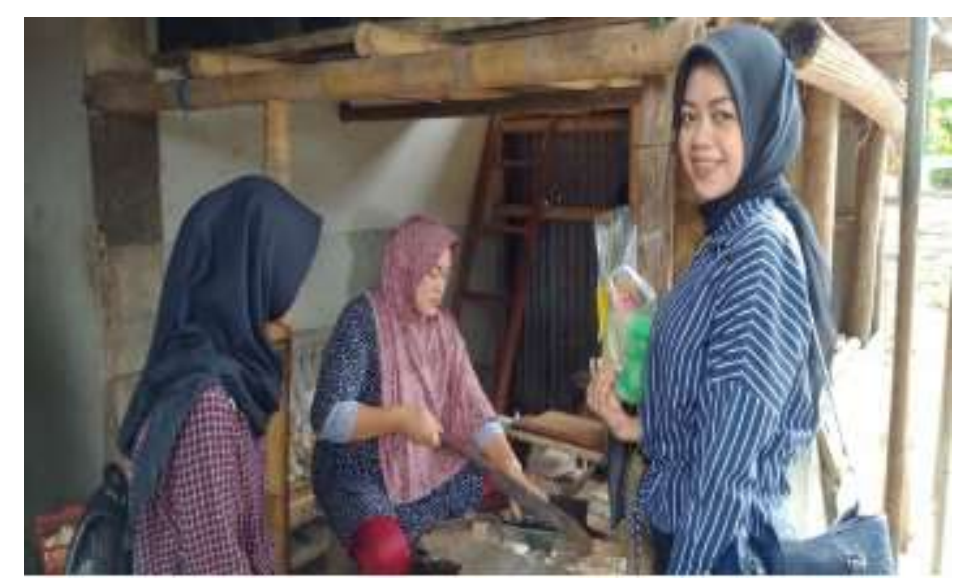

\section{Gambar 2. Hasil Kegiatan Pembenahan Disiplin kerja Karyawan}

Gambar 2 menjelaskan tentang pembenahan disiplin kerja yang lakukan dosen fakultas ekonomi kepada karyawan PD IKA. Pembenahan disiplin kerja dilakukan dengan pemnyuluhan pentingnya tepat waktu dalam bekerja dan ketepatan dalam 
menyelesaikan pekerjaan. Dosen dan mahasiswa hanya mampu memberikan penyuluhan dan tidak memonitoring pekerjaan karyawan karena dikhawatirkan akan mengganggu kinerja karyawan.

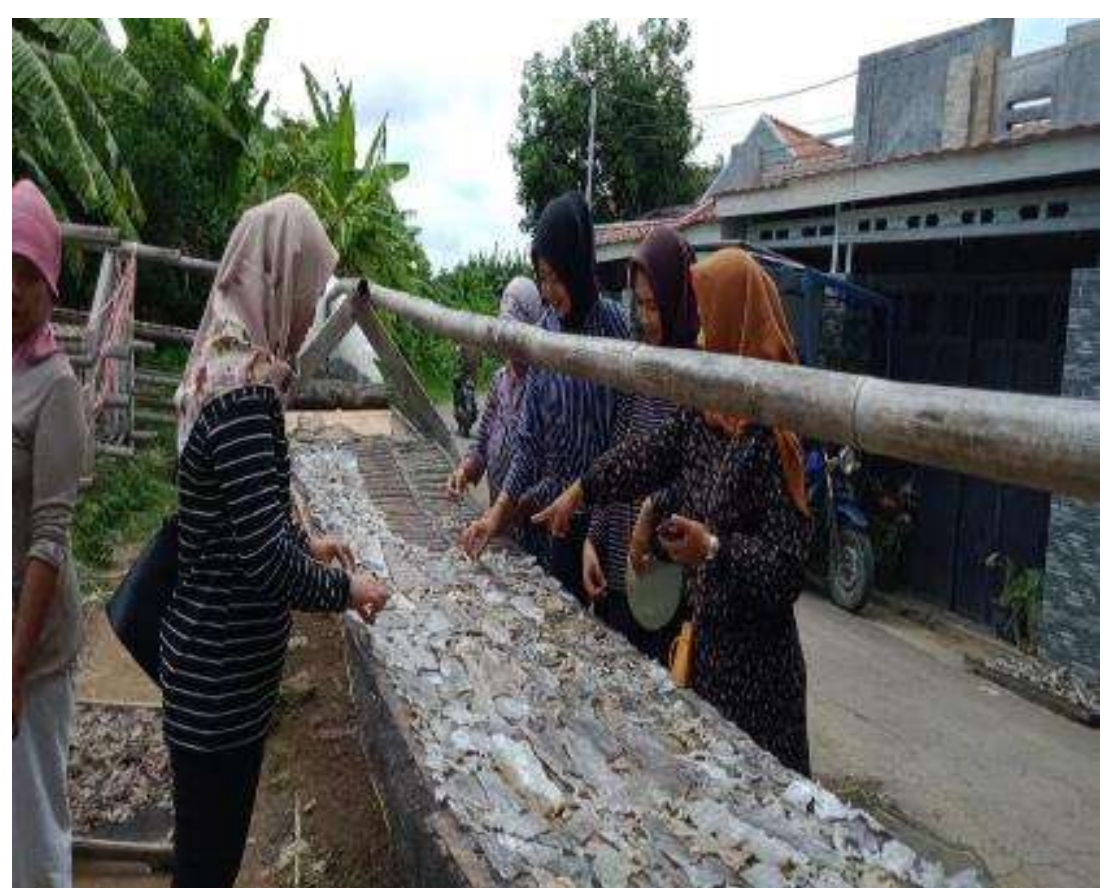

\section{Gambar 3. Kegiatan Terlibat Dalam Proses Pembuatan Krupuk Kulit}

Pada Gambar 3, mahasiswa dan dosen terlibat dalam proses pembuatan kulit krupuk. Kegiatan ini dilakukan untuk menentukan alokasi atau optimalisasi waktu pengerjaan produk dan optimalisasi hasil. Pelibatan mahasiswa dalam proses produksi dimulai dari pengelupasan kulit hingga proses pengemasan. 
ABDI WIRALODRA

JURNAL PENGABDIAN KEPADA MASYARAKAT
ISSN 2656-5501 (Print)

ISSN 2714-8041 (Online)

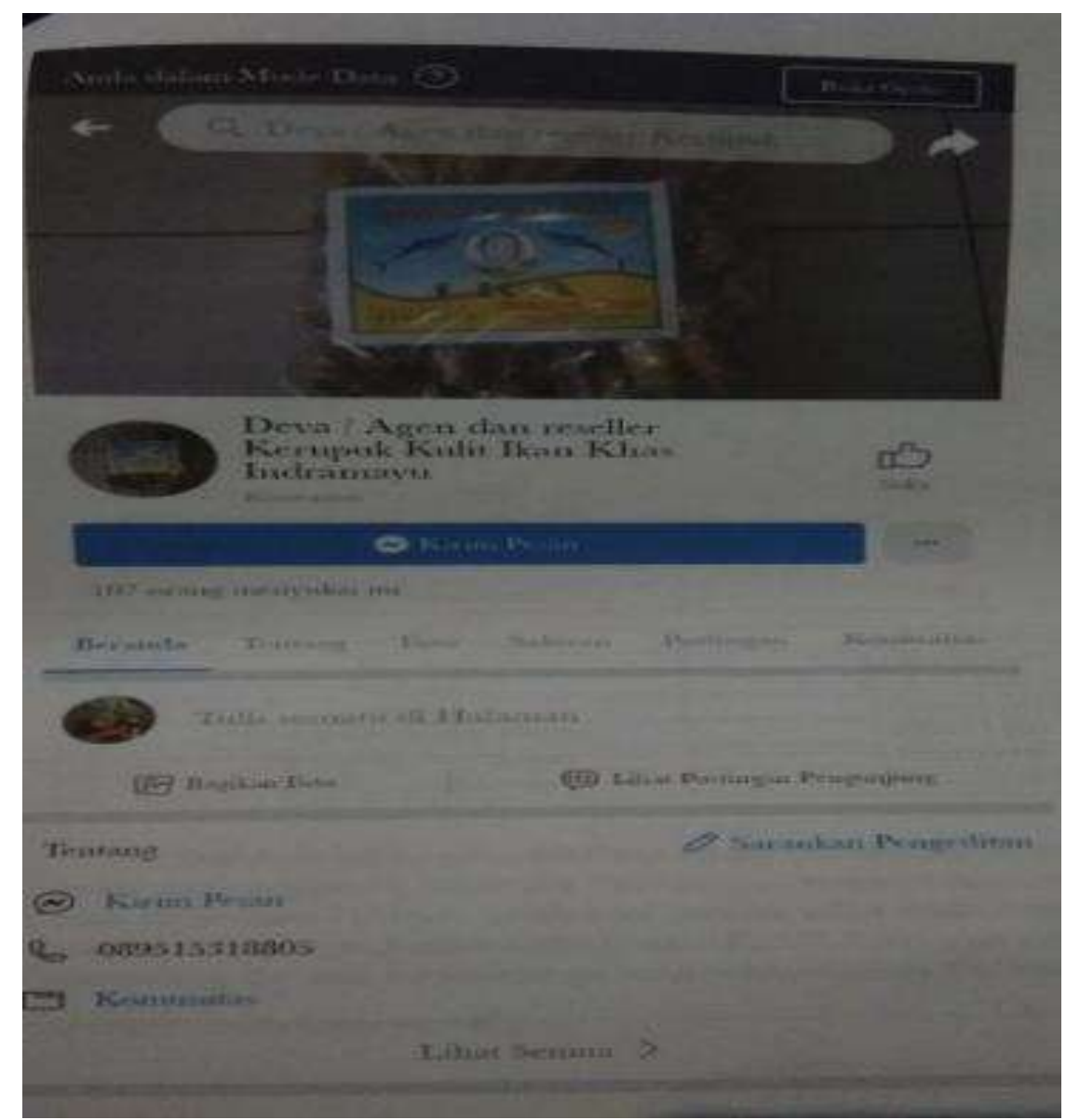

Gambar 4. Kegiatan Pembuatan Pemasaran Via Online

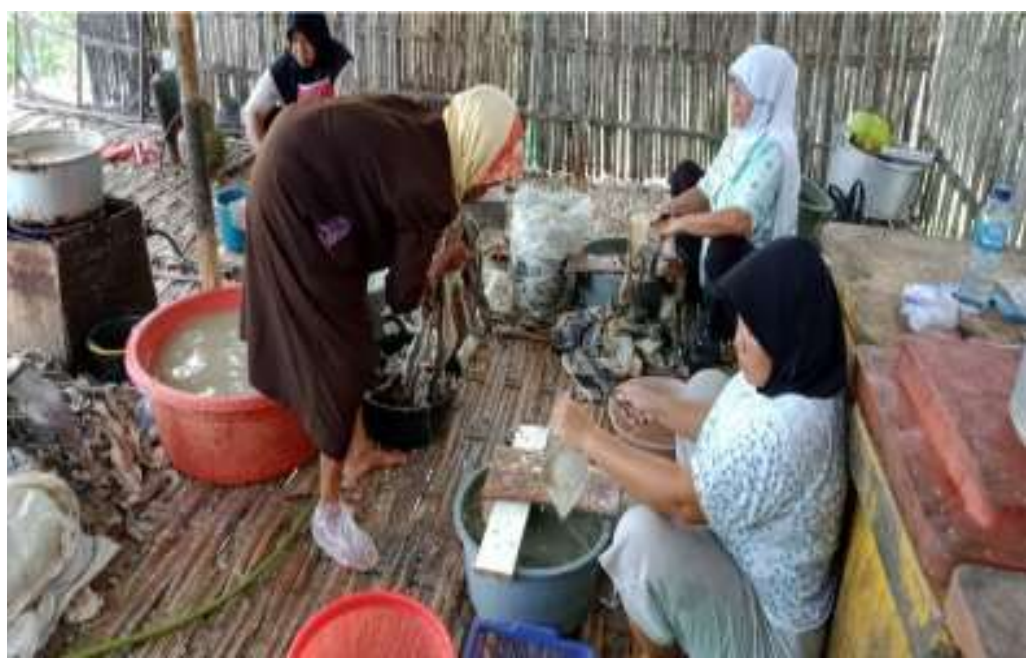

Gambar 5. Hasil Kegiatan Pembenahan Disiplin kerja Karyawan

Diterbitkan oleh Universitas Wiralodra 


\section{ABDI WIRALODRA}

JURNAL PENGABDIAN KEPADA MASYARAKAT
ISSN 2656-5501 (Print)

ISSN 2714-8041 (Online)

\section{KESIMPULAN}

Dari pembahasan di atas kami menyimpulkan dalam kegiatan Kuliah Kerja Usaha (KKU) ini masih tergolong belum maksimal karena ada beberapa aspek yang belum tercapai diantaranya mulai dari Aspek Keuangan yang belum tercapai dalam pembuatan laporan pembukuan Industri, Sedangkan dari Aspek Sumber Daya manusia nya sudah mulai tercapai dan diterapkan dalam Industri, dari Aspek pemasaran nya sendiri sudah tercapai, permasalahan yang ada bisa diatasi dan memberi alternatif untuk mengatasi nya seperti membuatkan akun pada media sosial yang bertujuan untuk memperluas ditribusi pemasarannya dan pembuatan kemasan yang lebih modern agar konsumen lebih tertarik pada produk yang dijual, dari Aspek Produksi/ Opresional sendiri mempunyai permasalahan faktor cuaca pada saat hujan dan dapat diatasi oleh Industri sendiri dengan alternatif pengeringan krupuk menggunakan mesin oven dan memperbanyak produksi pada saat cuaca tidak hujan agar mempunyai persediaan krupuk kering pada gudang.

\section{Ucapan Terima Kasih}

Ucapan terima kasih kepada Rektor Universitas Wiralodra yang telah memberikan izin mahasiswa fakultas ekonomi untuk melakukan KKU. Terima kasih kami ucapkan kepada Pemilik PD IKA yang telah bekerjasama dengan Fakultas Ekonomi Universsitas Wiralodra, dan terima kasih kepada seluruh mahasiswa dan semua pihak yang telah membantu dalam kegiatan KKU ini.

\section{Daftar Pustaka}

Bariyah, K. (1999). Implementasi Disiplin Kerja Dan Beban Kerja Terhadap Kinerja Karyawan. Jurnal Ilmiah.Fakultas Keguruan Dan Ilmu Pendidikan, 16(2), 27-36.

Jayanti Mandasari, D., Widodo, J., \& Djaja, S. (2019). Strategi Pemasaran Usaha

Mikro, Kecil Dan Menengah (Umkm) Batik Magenda Tamanan Kabupaten

Bondowoso. JURNAL PENDIDIKAN EKONOMI: Jurnal Ilmiah Ilmu

Pendidikan, Ilmu Ekonomi Dan Ilmu Sosial, 13(1), 123. 


\section{ABDI WIRALODRA}

JURNAL PENGABDIAN KEPADA MASYARAKAT
ISSN 2656-5501 (Print)

ISSN 2714-8041 (Online)

https://doi.org/10.19184/jpe.v13i1.10432

Khoirul Ulum, A. E., Suyadi, B., \& Hartanto, W. (2018). Pengaruh Lingkungan Kerja Dan Keterampilan Kerja Terhadap Produktivitas Kerja Karyawan Pada Pabrik Rokok Gagak Hitam Kecamatan Maesan Kabupaten Bondowoso. JURNAL PENDIDIKAN EKONOMI: Jurnal Ilmiah Ilmu Pendidikan, Ilmu Ekonomi Dan Ilmu Sosial, 12(2), 173-178.

https://doi.org/10.19184/jpe.v12i2.8311

Sari, N. N. M. P., \& Yasa, N. N. K. (2016). Peran Keunggulan Kompetitif Memediasi Orientasi Pasar Dengan Internasionalisasi UKM Mebel Di Kabupaten Badung. Jurnal Ekonomi Dan Bisnis, 5(6), 1651-1678.

Widayanti, R., Damayanti, R., \& Marwanti, F. (2017). Pengaruh Financial Literacy Terhadap Keberlangsungan Usaha (Business Sustainability) Pada Umkm Desa Jatisari. Jurnal Ilmiah Manajemen \& Bisnis, 18(2), 153-163. https://doi.org/10.30596/jimb.v18i2.1399 